\title{
Long-term safety and efficacy of Gamma Knife surgery in classical trigeminal neuralgia: a 497-patient historical cohort study
}

\author{
*Jean Régis, MD, ${ }^{1}$ Constantin Tuleasca, MD, ,2,3,6,7 Noémie Resseguier, MD, MSc, ${ }^{4}$ \\ Romain Carron, MD, PhD, ${ }^{1}$ Anne Donnet, MD, Jean Gaudart, MD, PhD, ${ }^{4}$ and \\ Marc Levivier, MD, PhD 6,7
}

${ }^{1}$ Functional and Stereotactic Neurosurgery Service and Gamma Knife Unit, Centre Hospitalier Universitaire La Timone Assistance Publique-Hopitaux de Marseille, Université de la Méditerranée, Marseille, France; ${ }^{2}$ Signal Processing Laboratory (LTS-5), Swiss Federal Institute of Technology, Lausanne, Switzerland; ${ }^{3}$ Medical Image Analysis Laboratory, Centre Hospitalier Universitaire Vaudois, Lausanne, Switzerland; ${ }^{2}$ Department of Public Health and Medical Information, Centre Hospitalier Universitaire La Timone, Assistance Publique-Hopitaux de Marseille, France; ${ }^{5}$ Department of Neurology, Clinical Neuroscience Federation, Centre Hospitalier Universitaire La Timone Assistance Publique-Hopitaux de Marseille, France; ${ }^{6}$ Department of Clinical Neurosciences, Neurosurgery Service and Gamma Knife Center, Centre Hospitalier Universitaire Vaudois, Lausanne, Switzerland; and ${ }^{7}$ Faculty of Biology and Medicine, University of Lausanne, Switzerland

OBJECTIVE Gamma Knife surgery (GKS) is one of the surgical alternatives for the treatment of drug-resistant trigeminal neuralgia (TN). This study aims to evaluate the safety and efficacy of GKS in a large population of patients with TN with very long-term clinical follow-up.

METHODS Between July 1992 and November 2010, 737 patients presenting with TN were treated using GKS. Data were collected prospectively and were further retrospectively evaluated at Timone University Hospital. The frequency and severity of pain, as well as trigeminal nerve function, were evaluated before GKS and regularly thereafter. Radiosurgery using the Gamma Knife (model B, C, 4C, or Perfexion) was performed with the help of both MR and CT targeting. A single 4-mm isocenter was positioned in the cisternal portion of the trigeminal nerve at a median distance of $7.6 \mathrm{~mm}$ (range 4-14 mm) anterior to the emergence of the nerve (retrogasserian target). A median maximum dose of $85 \mathrm{~Gy}$ (range 70-90 Gy) was prescribed.

RESULTS The safety and efficacy are reported for 497 patients with medically refractory classical TN who were never previously treated by GKS and had a follow-up of at least 1 year. The median age in this series was 68.3 years (range 28.1-93.2 years). The median follow-up period was 43.8 months (range 12-174.4 months). Overall, 456 patients $(91.75 \%)$ were initially pain free in a median time of 10 days (range 1-180 days). Their actuarial probabilities of remaining pain free without medication at $3,5,7$, and 10 years were $71.8 \%, 64.9 \%, 59.7 \%$, and $45.3 \%$, respectively. One hundred fifty-seven patients (34.4\%) who were initially pain free experienced at least 1 recurrence, with a median delay of onset of 24 months (range $0.6-150.1$ months). However, the actuarial rate of maintaining pain relief without further surgery was $67.8 \%$ at 10 years. The hypesthesia actuarial rate at 5 years was $20.4 \%$ and at 7 years reached $21.1 \%$, but remained stable until 14 years with a median delay of onset of 12 months (range 1-65 months). Very bothersome facial hypesthesia was reported in only 3 patients $(0.6 \%)$.

CONCLUSIONS Retrogasserian GKS proved to be safe and effective in the long term and in a very large number of patients. Even if the probability of long-lasting effects may be modest compared with microvascular decompression, the rarity of complications prompts discussion of using GKS as the pragmatic surgical first- or second-intention alternative for classical TN. However, a randomized trial, or at least a case-matched control study, would be required to compare with microvascular decompression.

http://thejns.org/doi/abs/10.3171/2015.2.JNS142144

KEY WORDS trigeminal neuralgia; Gamma Knife radiosurgery; safety; efficacy; stereotactic radiosurgery; pain

ABBREVIATIONS BNI = Barrow Neurological Institute; $\mathrm{CTN}=$ classical trigeminal neuralgia; $\mathrm{GKS}=$ Gamma Knife surgery; $\mathrm{MVD}=$ microvascular decompression; $\mathrm{TN}=$ trigeminal neuralgia.

SUBMITTED September 17, 2014. ACCEPTED February 3, 2015.

INCLUDE WHEN CITING Published online September 4, 2015; DOI: 10.3171/2015.2.JNS142144.

* Drs. Régis and Tuleasca contributed equally to this work. 
$\mathrm{T}$ RIGEMINal neuralgia (TN), also known as "tic douloureux," is a serious health problem with a prevalence of 12.6 per 100,000 people. ${ }^{44}$ Patients typically describe a severe and sudden pain in the face like an electric shock. While the etiology remains unclear, there is growing evidence supporting the fact that in most patients one of the main causal factors resides in the compression of the trigeminal nerve root, close to its entry into the pons by an aberrant arterial or venous loop. ${ }^{19}$

According to the most recent classification of the International Headache Society, ${ }^{10}$ classical trigeminal neuralgia (CTN) must be distinguished from symptomatic TN. CTN includes all cases without an established etiology, i.e., the idiopathic cases, as well as cases with potential vascular compression of cranial nerve V. ${ }^{10}$ Drug therapy is the first line of treatment and offers adequate pain relief in many patients. ${ }^{41}$ Carbamazepine (highest level of evidence) and oxcarbazepine (best tolerance) are the most commonly prescribed drugs for the treatment of TN. ${ }^{5}$ A minority of patients have hypersensitivity reactions, with some forms being associated with substantial morbidity and mortality. In Northern Europeans, the HLA-A*3101 allele is associated with carbamazepine-induced hypersensitivity reactions. ${ }^{20}$ Patients who do not respond to medical therapy or have intolerable adverse effects are suitable candidates for surgery. ${ }^{41}$ Surgical treatments include microvascular decompression (MVD), percutaneous ablative procedures that produce a partial lesion of the nerve (thermocoagulation, microcompression, and glycerol injection), and radiosurgery. ${ }^{21}$ MVD tackles the presumed cause by separating the offensive vessel loop from the trigeminal nerve and is currently considered as the gold-standard surgical treatment for drug-resistant TN.

Radiosurgery is a minimally invasive neurosurgical approach. The concept of radiosurgery was first introduced by Lars Leksell in 1951 when he treated a patient suffering from essential TN using a prototype guiding device linked to a dental x-ray machine. ${ }^{16}$ Later, Leksell conceived the Gamma Knife, a tool dedicated to radiosurgery that uses multiple focusing beams from cobalt- 60 sources. ${ }^{15}$ Several retrospective studies ${ }^{6,13}$ and a few prospective studies $^{32}$ have reported good short-term and midterm safety and efficacy of Gamma Knife surgery (GKS) for TN. GKS is known to be the least invasive neurosurgical approach for medically refractory TN. ${ }^{5,9}$ However, the long-term outcomes have not been well documented. $6,13,43$

\section{Methods}

\section{Type of Study}

The study was designed as an open, self-controlled, noncomparative study. ${ }^{30} \mathrm{~A}$ case report form was created and was completed prospectively when the first patient was treated at Timone University Hospital. Clinical examinations and MRI were performed (the later to exclude secondary cases). Data were retrospectively analyzed. Permission from the ethics committee was obtained for this historical cohort study.

\section{Patients}

From July 1992 through November 2010, 737 patients presenting with intractable $\mathrm{TN}$ were prospectively selected and treated with radiosurgery at Timone University Hospital in Marseille, France. A total of 497 patients had more than 1 year of follow-up. We excluded from our final analysis patients with TN secondary to multiple sclerosis,${ }^{37}$ megadolichobasilar artery compression, ${ }^{39}$ or a second GKS treatment, ${ }^{40}$ which are reputed to have more variable responses to radiosurgery and were beyond the scope of this study.

\section{Basic Demographic Data}

The median patient age was 68.3 years (range $28.1-93.2$ years); 225 patients (45.3\%) were men and $272(54.7 \%)$ were women. Pain was on the right side in 267 patients (53.7\%) and on the left side in 230 patients (46.3\%). Only 19 patients $(3.8 \%)$ had bilateral pain, but never simultaneously. Pain was predominantly distributed in the V2 territory of the trigeminal nerve $(29.4 \%)$, followed by V2 and V3 (24.5\%), V3 (19.5\%), V1 and V2 (13.9\%), V1, V2, and V3 (6.8\%), V1 (5.4\%), and V1 and V3 (0.02\%) territories (Table 1). All patients presented with typical pain according to further described criteria (i.e., TN1; please see Diagnostic Criteria Using the International Headache Society Definitions). The median time between pain onset and radiosurgery treatment was 68.3 months (range 6-531 months). Preoperative MRI revealed the presence of a vascular compression in 278 cases (55.9\%). Twentysix patients $(5.2 \%)$ died but were not excluded from the study because they had at least 1 year of follow-up, as did the other patients enrolled in the study.

\section{Details of Previous Treatments}

One hundred seventy-three $(34.8 \%)$ patients had prior surgical procedures, of which $102(20.5 \%)$ patients had only 1 previous intervention, $41(8.2 \%)$ patients had 2 previous surgeries, and $30(6 \%)$ had 3 or more previous surgeries.

Previous surgeries consisted of radiofrequency ablation in $99(19.9 \%)$ patients, balloon microcompression in 64 (12.9\%) patients, MVD in $45(9.1 \%)$ patients, and glycerol rhizotomy in $6(1.2 \%)$ patients.

Before GKS, 107 (21.5\%) patients had sensory disturbance in relation to a previous surgical procedure, which consisted of slight hypesthesia in $99(19.9 \%)$ and severe hypesthesia in $8(1.6 \%)$ patients. GKS was the first surgical procedure in 324 patients $(65.2 \%)$. All patients had drug-resistant TN or major intolerance to all therapies. Two hundred sixty-three patients $(52.9 \%)$ reported substantial side effects to drug therapy at the time of radiosurgery.

\section{Diagnostic Criteria Using the International Headache Society Definition}

All patients fulfilled the criteria of the International Headache Society. ${ }^{10}$ Evaluation of the type of TN was made according to the classifications proposed by Eller et al. ${ }^{7}$ and comprised idiopathic TN1 and TN2. TN1 is described as typically sharp, shooting, electrical shock like, with pain-free intervals between attacks that is present for more than $50 \%$ of the time; TN2 is described as an ach- 
TABLE 1. Clinical preoperative and demographic data

\begin{tabular}{|c|c|}
\hline Variable & Value* $^{*}$ \\
\hline \multicolumn{2}{|l|}{ Sex } \\
\hline Male & $225(45.3)$ \\
\hline Female & $272(54.7)$ \\
\hline Median age (yrs) (range) & $68.3(28.1-93.2)$ \\
\hline Median duration of follow-up (mos) (range) & $43.8(12-174.4)$ \\
\hline \multicolumn{2}{|l|}{ Side of pain } \\
\hline Right & $267(53.7)$ \\
\hline Left & $230(46.3)$ \\
\hline \multicolumn{2}{|l|}{ Pain distribution } \\
\hline V2 & $146(29.4)$ \\
\hline V2 \& V3 & $122(24.5)$ \\
\hline V3 & $97(19.5)$ \\
\hline V1 \& V2 & $69(13.9)$ \\
\hline V1 \& V2 \& V3 & $34(6.8)$ \\
\hline V1 & $27(5.4)$ \\
\hline V1 \& V3 & $1(0.02)$ \\
\hline $\begin{array}{l}\text { Preop MRI vascular conflict (other than } \\
\text { megadolichobasilar compression) }\end{array}$ & $278(55.9)$ \\
\hline No prior surgery & $324(65.2)$ \\
\hline Prior surgery & $173(34.8)$ \\
\hline 1 & $102(20.5)$ \\
\hline 2 & $41(8.2)$ \\
\hline$\geq 3$ & $30(6)$ \\
\hline \multicolumn{2}{|l|}{ Type of prior surgery } \\
\hline Radiofrequency lesion & $99(19.9)$ \\
\hline Balloon microcompression & $64(12.9)$ \\
\hline Microvascular decompression & $45(9.1)$ \\
\hline Glycerol rhizotomy & $6(1.2)$ \\
\hline Side effects from prior surgery & $107(21.5)$ \\
\hline \multicolumn{2}{|l|}{ Facial sensitivity before GKS } \\
\hline Normal & $393(79.1)$ \\
\hline Slight hypesthesia & 96 (19.3) \\
\hline Severe hypesthesia & $8(1.6)$ \\
\hline Anesthesia & $1(0.02)$ \\
\hline
\end{tabular}

* Values indicate the number of patients (\%) unless otherwise indicated.

ing, throbbing, or burning pain that is present for more than $50 \%$ of the time and is constant in nature (constant background pain being the most significant attribute). Only patients fulfilling the criteria for the TN1 type were included. The preoperative MRI protocol included 3D T1weighted images, with and without contrast, and T2 CISS (constructive interference in steady state) without contrast.

\section{Brief Description of the Operative Technique}

All patients underwent GKS. After application of the Leksell model G stereotactic frame (Elekta Instruments AB) under local anesthesia, all patients underwent stereotactic MRI and CT for target definition. The MRI sequences used to identify the trigeminal nerve were T2type semi-millimetric CISS (Siemens) without contrast and contrast-enhanced T1-weighted images. Bone CT routinely supplements the neuroradiological investigation to correct any distortion errors on the MRI images. ${ }^{32,38}$

Between July 1992 and November 2010, models B, C, $4 \mathrm{C}$, or Prefexion of the Gamma Knife were successively used (Elekta Instruments AB).

A single 4-mm isocenter was used in all patients and positioned in the anterior cisternal portion of the trigeminal nerve at a median distance of $7.6 \mathrm{~mm}$ (range 4-14 mm) anterior to the emergence of the nerve (retrogasserian target). This target has been classically used in our center since the beginning of GKS treatments for TN, as detailed in previous studies. ${ }^{29,30,32,33}$

The median value of the maximum dose delivered was 85 Gy (70-90 Gy). Furthermore, we initially give a dose of $90 \mathrm{~Gy}$ at the $100 \%$ isodose. Beam channel blocking is used depending on the maximal dose received by $10 \mathrm{~mm}^{3}$ of the brainstem. If this dose is more than $15 \mathrm{~Gy}$, we diminish the dose, and then if still necessary we start beam channel blocking to make it possible for us to avoid the so-called "Flickinger effect" (increasing the mean dose to the nerve also increases toxicity). ${ }^{8}$ All interventions were performed by the senior neurosurgeon (J.R.).

\section{Follow-Up Monitoring}

Initial follow-up was based on clinical evaluations performed at regular intervals of 3 months, 6 months, and 1 year after the treatment and on a yearly basis thereafter. All patients were seen in person for the proper evaluation of safety and efficacy, including facial sensory testing, corneal reflex, and jaw motility. For long-term follow-up updates, telephone interviews were considered acceptable for patients unable to visit us either because of distance or general health-related conditions.

The patients and referring doctor were instructed to continue the medication unchanged for at least 1 month, and then were instructed to diminish the drug doses progressively in cases of pain freedom. Every clinical evaluation made by our medical team during the follow-up course was prospectively noted in the database so that we had continuous and prospective up-to-date information. The 15 types of essential data, as considered by Zakrzewska and Thomas ${ }^{48}$ for articles reporting the outcomes of the surgical treatment for TN, were followed and are presented hereafter. At our center, systematic MR follow-up has never been part of our protocol.

\section{Explicit Definitions of Outcome Measures}

Outcome measures included initial pain freedom, onset of the sensory disturbance, recurrence, and recurrence without further surgery. Efficacy is reported according to the Barrow Neurological Institute (BNI) scale (Class I, no trigeminal pain and no medication; Class II, occasional pain not requiring medication; Class IIIa, no pain but continued medication; Class IIIb, controlled with medication; Class IV, some pain but not adequately controlled with medication; Class V, severe pain and no pain relief). A successfully treated patient was pain free without medication (BNI Class I).

The degree of hypesthesia is reported using the BNI fa- 
cial hypesthesia scale (Class I, no facial numbness; Class II, mild facial numbness and not bothersome; Class III, facial numbness and somewhat bothersome; Class IV, facial numbness and very bothersome). ${ }^{34}$ The corneal reflex was assessed in all patients. Additionally, the appearance of dysesthesias, allodynias, paresthesias, anesthesia dolorosa, masseteric weakness, neurological complications outside of the trigeminal nerve territory, systemic complications, and death were carefully noted.

Recurrence was defined as change from Class I to a lower outcome class. Thus, the situation of a patient who had been pain free without medication (Class I) and who then restarted taking specific drugs but who remained pain free on medication (Class II) was considered as a recurrence.

The latency intervals to becoming pain free or developing recurrence or a sensory disturbance, the dates of medication changes, and the dates of further surgical procedures were also carefully monitored.

\section{Definition of Minor and Major Recurrence}

A minor recurrence was defined as one that was well tolerated by the patient (lower pain frequency and intensity) that did not require a new surgical therapy. A major recurrence was defined as requiring a further surgical procedure. We use the term "initial efficacy" when a patient is pain free with or without medication in the first 6 months after the radiosurgery and has no recurrence in the year that follows the procedure.

The probability of maintaining pain relief with further surgery will be separately reported in our clinical study.

\section{Patient Satisfaction}

Patient satisfaction was evaluated at the last follow-up through a simple questionnaire. The items proposed as an answer in our semistructured questionnaire included: "No regret, I would have radiosurgery again with no hesitation;" "No opinion;" and "I regret performing radiosurgery (and would not do it again)."

\section{Statistical Analysis}

All statistical analyses were performed using R software (version 2.12.0, $\mathrm{R}$ Foundation for Statistical Computing). The survival $\mathrm{R}$ package was used for the survival analysis. For the evaluation of outcomes such as pain free, hypesthesia, and recurrence, the time-to-event was estimated using the Kaplan-Meier method. Bivariate analysis was then performed to identify the predictive factors among the collected variables. For qualitative variables, Kaplan-Meier curves were used to graphically represent survival among the different groups and compared using the univariate log-rank test. For all variables, the effects were estimated and tested by fitting univariate Cox proportional hazards regression models. The proportionality of the hazards was assessed graphically by log cumulative hazard plots. For qualitative variables, the chi-square test was performed when valid; otherwise the exact Fischer test was used. For quantitative variables, the Mann-Whitney test was performed given the number of patients. All tests were 2 -sided, and $\mathrm{p}$ values $<0.05$ were judged to be significant.

\section{Results}

\section{Details of Follow-Up Period}

The median follow-up period was 43.8 months (range 12-174.4 months).

\section{Initial Rate of Pain Freedom Response}

Four hundred fifty-six patients $(91.75 \%)$ were initially pain free in a median time of 10 days (range 1-180 days). The initially pain-free actuarial rates at $0.5,1,2,3,4,5$, and 6 months were $53.52 \%, 73 \%, 83.5 \%, 88.1 \%, 88.9 \%$, $89.5 \%$, and $91.75 \%$, respectively (Fig. 1; with the flat part of the curve being practically reached at 6 months).

The following characteristics showed a negative and statistically significant difference: previous surgical intervention ( $\mathrm{p}=0.005$, HR 0.24 , and 95\% CI $0.09-0.65)$, only 1 previous surgical intervention $(\mathrm{p}=0.009$, HR 0.16, and $95 \%$ CI $0.04-0.64)$, and a previous history of MVD ( $\mathrm{p}=$ 0.01 , HR 0.64).

Differences in age $(p=0.172)$, time elapsed until treatment onset $(p=0.731)$, and the sides of pain $(p=0.4)$ were not statistically significant.

\section{Postoperative Sensory Assessment: Details of Other Postoperative Complications}

No patient experienced an early complication after GKS. Seventy-two patients (21.1\% actuarial rate) later developed sensory dysfunction such as paresthesias or objective facial sensory loss, which occurred especially during the first 5 years after GKS. The time of onset of hypesthesia occurred at a median of 12 months (range 1-65). Patients had either mild hypesthesia in $49(8.3 \%)$ cases or severe in $23(4.6 \%)$ cases. We also assessed hypesthesia using the BNI facial hypesthesia scale: mild facial numbness in 61 (12.3\%) patients; facial numbness that

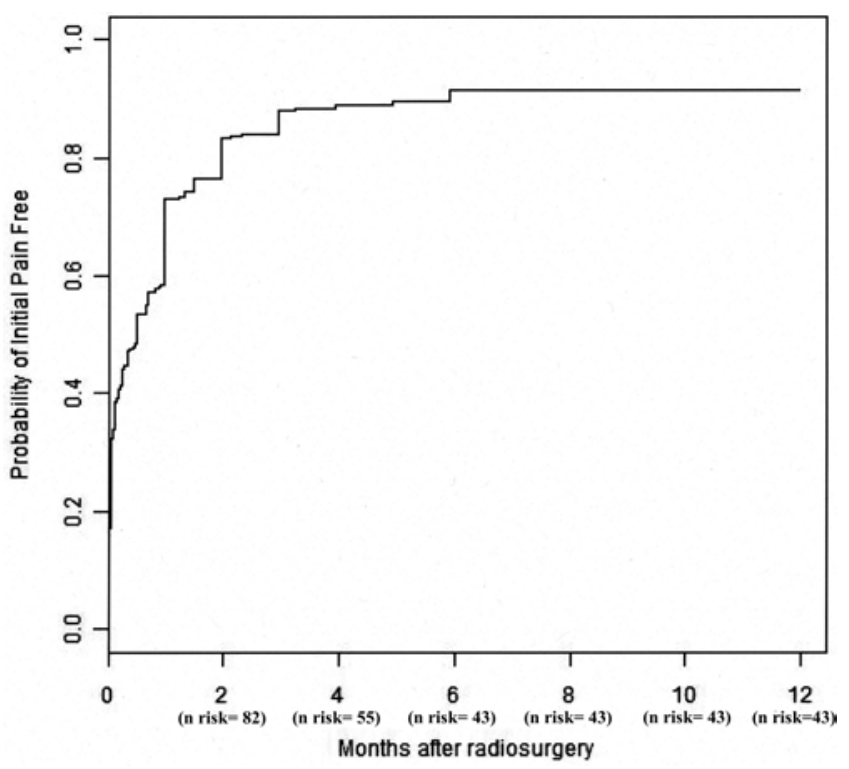

FIG. 1. Probability of an initial pain-free onset depending on the time since GKS. The probability of being initially pain free reaches a plateau at 6 months (with a rate of freedom from pain of $91.75 \%$ ). The initial pain-free actuarial rates at $0.5,1,2,3,4,5$, and 6 months were $53.52 \%$, $73 \%, 83.5 \%, 88.1 \%, 88.9 \%, 89.5 \%$, and $91.75 \%$, respectively. 
was somewhat bothersome in $8(1.6 \%)$ patients; and facial numbness that was very bothersome in $3(0.6 \%)$ patients.

The 3 patients with very bothersome hypesthesia said that their quality of life was worse and that this dysfunction was not a good tradeoff, whereas the majority of the patients who developed numbness after GKS (69 of 72 patients; 95.8\%) considered that their quality of life improved after GKS and that the sensory dysfunction was a good tradeoff for pain relief.

The hypesthesia actuarial rates at $0.5,1,2,3,5$, and 7 years were $6.4 \%, 10.2 \%, 16.8 \%, 18.3 \%, 20.4 \%$, and $21.1 \%$, respectively, and remained stable for 14 years (Fig. 2). No patients developed a trigeminal motor deficit after GKS or other cranial nerve deficits. There were 0 cases of anesthesia dolorosa or dry-eye syndrome.

\section{Management and Results of Recurrent Pain}

One hundred fifty-seven $(34.4 \%)$ of the patients who were initially pain free (456 patients) experienced at least 1 recurrence after GKS. The median time to recurrent pain was 24 months (range 0.6-150.1 months). Because of recurrent medically refractory pain, $112(22.5 \%)$ patients required further surgeries. Eighty-five (17.1\%) patients required only 1 further surgery, 21 (4.2\%) required 2 further surgeries, and $6(1.6 \%)$ required 3 or more surgeries.

In our unit, the most common intervention after failed GKS was balloon microcompression, which was performed in $61(12.3 \%)$ patients, followed by thermocoagulation in $29(5.8 \%)$ patients, MVD in 21 (4.2\%) patients, and glycerol rhizotomy in $1(0.02 \%)$ patient (Table 2$)$.

Usually, in our clinic, if a first-intention MVD treatment was proposed but declined by the patient in the absence of efficacious GKS, it is usually proposed again and frequently accepted by the patient.

The actuarial probabilities of maintaining pain relief

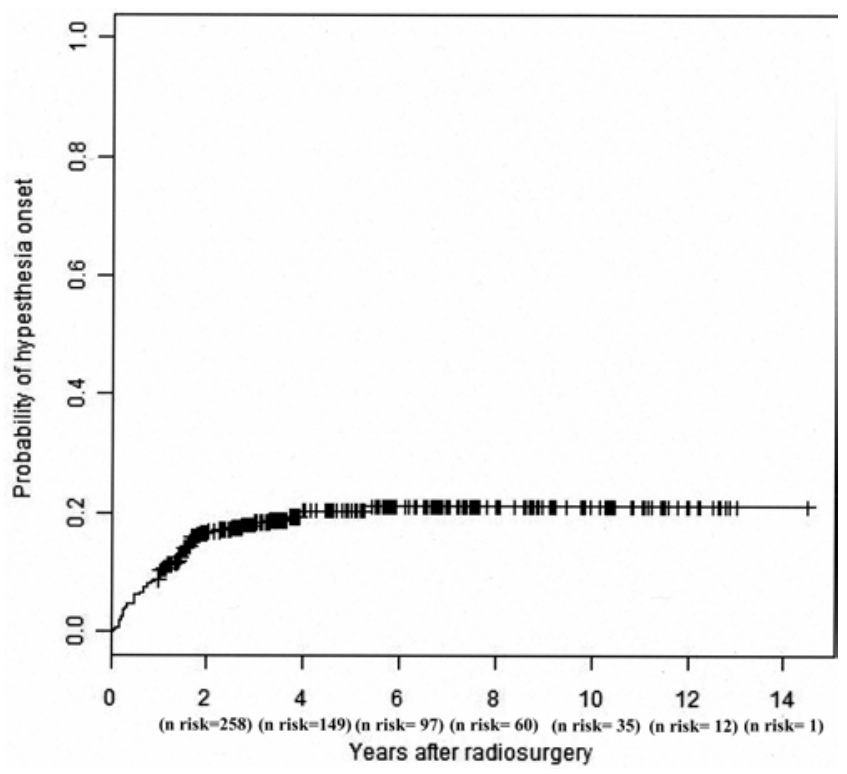

FIG. 2. Actuarial probability of having new-onset hypesthesia depending on the time since GKS. The hypesthesia actuarial rates at $0.5,1,2$, 3,5 , and 7 years were $6.4 \%, 10.2 \%, 16.8 \%, 18.3 \%, 20.4 \%$, and $21.1 \%$, respectively, and remained stable for 14 years.
TABLE 2. Postoperative assessment

\begin{tabular}{lc}
\hline \multicolumn{1}{c}{ Variable } & Value* \\
\hline Initially pain free & $456(91.75)$ \\
\hline Post-GKS sensory dysfunction & $72(14.5)$ \\
\hline Mild & $49(9.8)$ \\
\hline Severe & $23(4.6)$ \\
\hline BNI facial hypesthesia scale & $425(85.5)$ \\
\hline No facial numbness & $61(12.3)$ \\
\hline Mild facial numbness & $8(1.6)$ \\
\hline Facial numbness, somewhat bothersome & $3(0.6)$ \\
\hline Facial numbness, very bothersome & $157(34.4)$ \\
\hline Recurrence of pain & $24(0.6-150.1)$ \\
\hline Median time to pain recurrence in mos (range) & $112(22.5)$ \\
\hline Additional treatment after GKS & \\
\hline No. of treatments & $85(17.1)$ \\
\hline 1 & $21(4.2)$ \\
\hline 2 & $6(1.2)$ \\
\hline$\geq 3$ & $61(12.3)$ \\
\hline Type of treatment & $29(5.8)$ \\
\hline Balloon microcompression & $21(4.2)$ \\
\hline Radiofrequency lesion & $1(0.02)$ \\
\hline Microvascular decompression
\end{tabular}

* Values indicate the number of patients (\%) unless otherwise indicated.

without medication at $0.5,1,2,3,5,7,10,12$, and 14 years were $93.4 \%, 85.9 \%, 78.6 \%, 71.8 \%, 64.9 \%, 59.7 \%, 45.3 \%$, $40.7 \%$, and $33.9 \%$, respectively (see Fig. 3). Having three or more previous surgeries was a factor associated with decreased long-term efficacy ( $p=0.0163$; HR 1.98; $95 \%$ CI 1.13-3.47) in comparison with patients having undergone fewer than 2 prior surgeries. Post-GKS hypesthesia onset was associated with a higher probability of maintaining pain relief ( $p=0.0003$; HR 0.27; 95\% CI 0.13-0.56).

\section{Probability of Maintaining Pain Relief Without Further Surgery}

The actuarial probabilities of maintaining pain relief without further surgery at $0.5,1,2,3,5,7$, and 10 years were $96.1 \%, 92.1 \%, 88.1 \%, 84.2 \%, 79.7 \%, 75.4 \%$, and $67.8 \%$, respectively, and remained stable through 14 years (Fig. 4). We found statistically significant data for 3 or more previous surgeries ( $\mathrm{p}=0.007$; HR 2.64; $95 \% \mathrm{CI}$ $1.3-5.37)$ and the presence of post-GKS hypesthesia $(\mathrm{p}=$ 0.006; HR 0.06; 95\% CI 0.01-0.46).

\section{Postoperative Patient Satisfaction}

The vast majority of patients $(93.8 \%)$ expressed a high level of satisfaction, did not regret undergoing GKS, and would undergo the procedure again. A minority of the patients had no opinion (4.6\%), and $2.3 \%$ would not undergo the procedure again.

\section{Discussion}

There are several neurosurgical therapeutic options for 


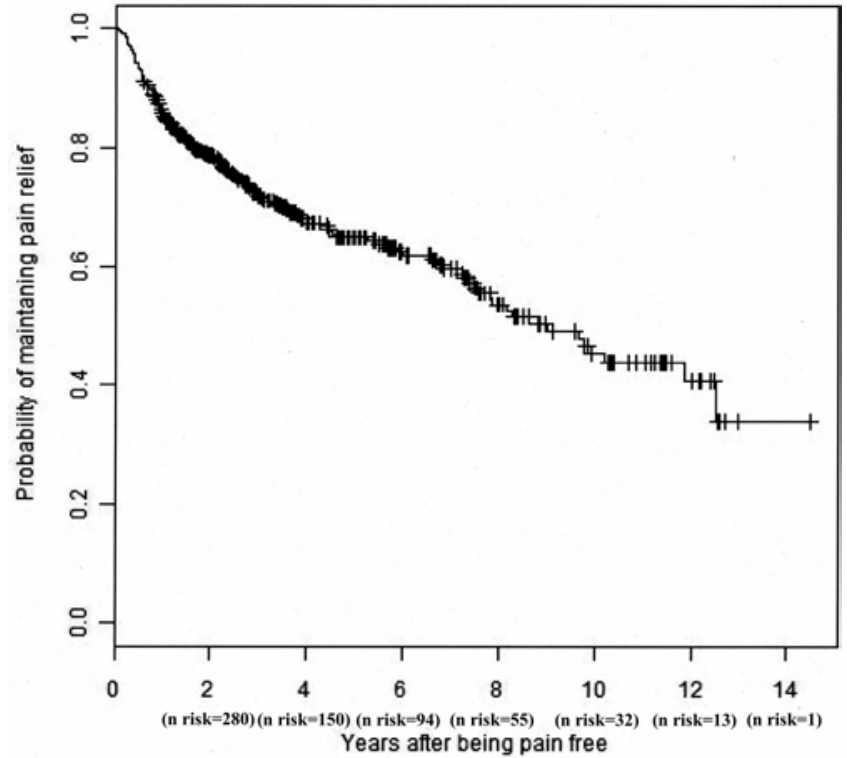

FIG. 3. Actuarial probability of maintaining pain relief without medication. The actuarial probabilities of maintaining pain relief at $0.5,1,2,3,5,7$, 10,12 , and 14 years were $93.4 \%, 85.9 \%, 78.6 \%, 71.8 \%, 64.9 \%, 59.7 \%$, $45.3 \%, 40.7 \%$, and $33.9 \%$, respectively.

drug-resistant CTN. Radiosurgery was first used for TN treatment in the 1960 s by Lars Leksell. ${ }^{16}$ Its safety and efficacy started to be evaluated in the early 1990s, including by our team..$^{28,31}$ A cornerstone paper was the multicentric study of Kondziolka et al., which appeared in $1996^{12}$ and generated a profound paradigm shift in radiosurgical practice. ${ }^{33}$ The reappraisal of radiosurgery for TN in the $1990 \mathrm{~s}$ was made possible by the development of high-resolution MRI, which enabled the proper visualization of the cisternal portion of cranial nerve $\mathrm{V} .{ }^{30,33}$ Radiosurgery is currently regarded as the least invasive neurosurgical approach for TN. ${ }^{5,9,44}$ A trigeminal nerve deficit usually appears within the first 2 years after radiosurgery, but has also been reported as late as 5 years after treatment. ${ }^{13}$ The only side effect reported in our long-term study is trigeminal nerve sensory disturbance. Only $21.5 \%$ of the patients reported this side effect, and the vast majority did not consider it as bothersome or disabling. The mechanisms of action of radiosurgery for TN are not known. Several authors have reported a higher rate of pain relief in patients experiencing hypesthesia..$^{25}$ However, contrary to the percutaneous techniques, it is noteworthy to point out that the majority of the patients experiencing long-term pain freedom in our study did not report hypesthesia. Consequently, we do not consider hypesthesia necessary for the efficacy of radiosurgery. In the meta-analysis by Gronseth et al., ${ }^{9}$ the rate of hypesthesia reported after radiosurgery is similar to the rate of hypesthesia after MVD and much lower than the rate of hypesthesia reported after percutaneous ablative procedures. This observation suggests that radiosurgery may involve a mechanism of action that is more subtle than a purely destructive one.

The technical nuances of GKS have a major impact on the clinical outcome of radiosurgery for TN. ${ }^{33}$ Pain control increases according to the dose prescription, but a larger

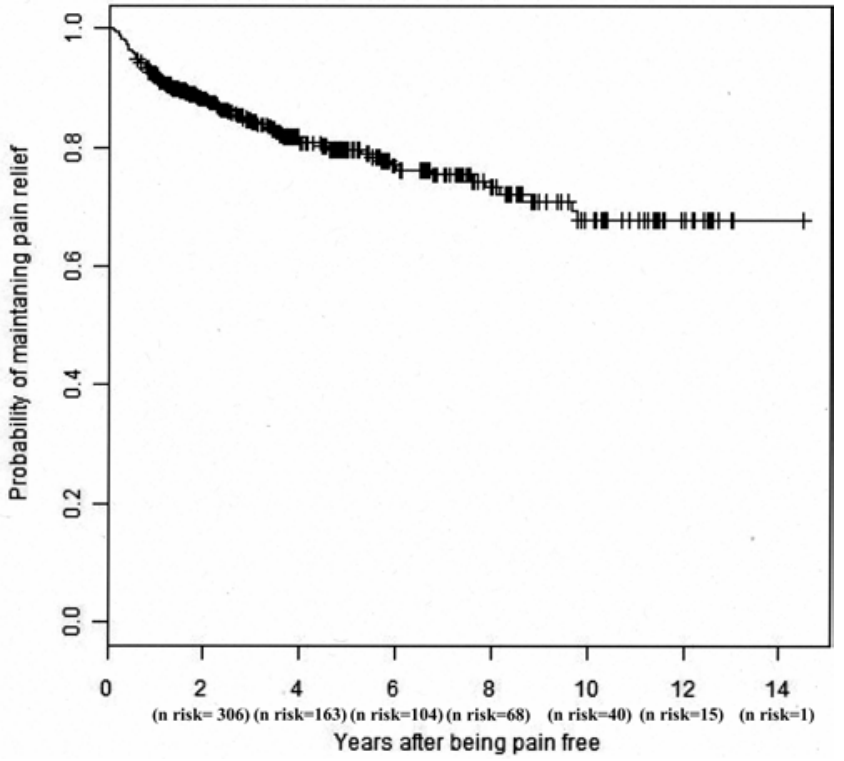

FIG. 4. Actuarial probability of maintaining pain relief without new surgery depending on the time since pain cessation. The actuarial probabilities of maintaining pain relief without further surgery at $0.5,1,2,3$, 5,7 , and 10 years were $96.1 \%, 92.1 \%, 88.1 \%, 84.2 \%, 79.7 \%, 75.4 \%$, and $67.8 \%$, respectively, and remained stable for 14 years.

volume of nerve treated has been reported to dramatically increase the toxicity (i.e., the risk of bothersome hypesthesia) without increasing the rate of pain relief. ${ }^{8}$ Also, a target placed close to the brainstem at the level of the root entry zone ${ }^{26}$ seems to be associated with a higher risk of numbness and higher risk of bothersome hypesthesia. This fact is confirmed by the recent paper by Sheehan et al. ${ }^{42}$ who found more numbness in a group of patients where the target used was the so-called dorsal root entry zone in comparison with the more anterior cisternal target that the authors used later on in their series. The major impact of these technical nuances may explain the large variability in the safety and efficacy reported in the literature. Of note, the remarkable high response rate in our series (initial pain freedom rate of $91.3 \%$ at 6 months) and low hypesthesia rate on a long-term basis are likely due to the use of a high maximum prescription dose (median $85 \mathrm{~Gy}$ ) and use of the "anterior retrogasserian target."

There are only 3 studies reporting long-term outcome after GKS. ${ }^{6,13,43}$ Dhople et al. ${ }^{6}$ described the outcomes for 102 patients, with a median follow-up of 5.6 years (range 13-115 months). The target was the dorsal root entry zone with a median maximal dose of 75 Gy (range 70-80 Gy). Regarding the classical outcomes, the initial pain freedom rate was $81 \%$, bothersome hypesthesia rate was $6 \%$ (the global rate not reported), and the probabilities of maintaining pain relief at 3,5, and 7 years were $41 \%, 34 \%$, and $22 \%$, respectively.

Kondziolka et al. ${ }^{13}$ reported the outcomes for 503 patients, of whom 107 had more than 5 years of follow-up. The target was placed at " $3-8 \mathrm{~mm}$ anterior from the junction of the trigeminal nerve and pons." The maximal dose delivered was 80 Gy. Regarding the classical outcomes: the initial pain freedom rate was $89 \%$; sensory dysfunction 
appeared in $10.5 \%$ of patients with 1 case of deafferentation pain (in a patient who already had decreased facial sensation after previous MVD); and the probabilities of maintaining pain relief at 3,5 , and 10 years were $71 \%$, $46 \%$, and $30 \%$, respectively.

Young et al. ${ }^{43}$ reported outcomes for 315 patients with a mean duration of follow-up of $68.9 \pm 41.8$ months. The target was placed "on the trigeminal nerve, with the $20 \%$ isodose line tangential to the pontine surface." All patients were treated with a maximal dose of 90 Gy. Regarding the classical outcomes, initial pain-freedom rate was found in $85.6 \%$ of cases, and hypesthesia was found in $32.9 \%$ (and very bothersome in $4.5 \%$ ) of cases. Furthermore, dry-eye syndrome was encountered in $22.4 \%$ and jaw weakness in $11.2 \%$ of patients.

The gold-standard neurosurgical procedure is MVD. Although no prospective randomized trial exists, MVD seems to be the approach that provides the highest chance of maintaining long-term pain relief. ${ }^{17,27} \mathrm{MVD}$ is not expected to damage the nerve, but presumably acts by alleviating the pathophysiological cause of $\mathrm{TN}$, namely, compression of the trigeminal nerve by a vascular loop. MVD carries a small but definite risk of major, including fatal, complications. In 1996, Barker et al. ${ }^{1}$ reported the retrospective evaluation of a large cohort of 1155 patients treated with MVD and followed up for at least 1 year (median follow-up 6.2 years). Thirty percent of the patients experienced recurrence of pain. Due to severe recurrence, $11 \%$ of patients underwent a second operation. The major complications reported by the authors included 2 postoperative deaths $(0.2 \%), 1$ brainstem infarction $(0.1 \%), 4$ intracerebral hematomas, 4 cerebellar edemas, 2 cases of hydrocephalus, 12 cases of facial palsy ( 2 permanent), 15 cases of extraocular muscle palsy ( 2 permanent), 16 cases of ipsilateral hearing loss, 22 cases of severe facial numbness, 20 cases of CSF leakage, 4 cases of pseudomeningocele, 5 cases of bacterial meningitis, 225 cases of chemical meningitis, 2 cases of pneumonia, and 1 case each of septicemia, myocardial infarction, transverse sinus thrombosis, pulmonary embolus, and permanent contralateral hearing loss. ${ }^{1}$ Few other reports ${ }^{2,24,47,48}$ used independent outcome assessments after MVD. ${ }^{5}$ These case series confirm the results of Barker et al., with a $75 \%$ chance of maintaining pain relief at 3 years and a risk of operative mortality of $0.2 \%$ (rising to $0.5 \%$ in other reports). ${ }^{1} \mathrm{Ma}-$ jor problems such as CSF leakage, infarcts, or hematomas are reported in $4 \%$ of the patients, and aseptic meningitis in $11 \%$; diplopia due to injury to cranial nerves IV and VI (most frequently transient) and facial palsy are rare., ${ }^{2,47}$ Ipsilateral hearing loss is a major long-term complication that has been reported in as many as $10 \%$ of patients..$^{2,47}$ Sensory loss is observed in $7 \%$ of patients.

Percutaneous techniques (thermocoagulation, balloon microcompression, and glycerol injection) share an ablative mechanism of action. All of these procedures require brief general anesthesia, the penetration of a probe through the foramen ovale under fluoroscopic control or navigation, and a physical action (thermal, mechanical, or chemical) on the fibers of cranial nerve $\mathrm{V}$ at the level of the gasserian ganglion. Generating a certain level of hypesthesia is classically necessary for the complete and prolonged efficacy of these techniques. Thus, all these percutaneous techniques are associated with a high rate of more or less disabling trigeminal nerve dysfunction. In the main series of the literature (see Lopez et al. ${ }^{18}$ ), the 3 -year actuarial rate of complete pain relief has been reported as $58 \%$ to $64 \%$ for radiofrequency thermocoagulation, ${ }^{8,45}$ $53 \%$ to $54 \%$ for glycerol rhizolysis, ${ }^{23,36}$ and $69 \%$ for balloon microcompression. ${ }^{3}$ Masticatory weakness has been reported in $12 \%$ of patients after thermocoagulation ${ }^{14,18,45}$ and in $3 \%$ after glycerol rhizolysis. ${ }^{23,35,36}$ Troublesome dysesthesia has been reported in $4 \%$ of patients after thermocoagulation, ${ }^{11,14,45}$ in $8.5 \%$ after glycerol rhizolysis, ${ }^{4,23}$ and in $10 \%$ after balloon microcompression. ${ }^{22}$ Anesthesia dolorosa has been reported in $1.5 \%$ of patients after thermocoagulation, ${ }^{11,14,45} 2.5 \%$ after glycerol rhizolysis ${ }^{23,35,36}$ and has not been reported after balloon microcompression. ${ }^{22}$ Keratitis is observed was $1.5 \%$ of patients after thermocoagulation $^{11,14,45}$ and $2 \%$ after glycerol rhizolysis ${ }^{23,35,36}$ but was not reported after balloon microcompression. ${ }^{22}$ It is important to note that with all these neurosurgical procedures, postoperative morbidity is lower in high-volume units.

Very few Level I evidence papers concerning the evaluation of the different surgical techniques for the treatment of TN are available. ${ }^{44}$ The quality of reporting evaluations of surgical treatments for TN rarely follow the recommendations published in 2003 by Zakrzewska and Lopez. ${ }^{46}$

\section{Conclusions}

The present study is unique due to the fact that the data were collected in a prospective fashion, the cohort is very large, and a long-term follow-up was conducted; however, this study is still limited by the absence of randomization. This series represents, to date, the study with the largest case series available and has the advantage of a very longterm follow-up. Additionally, this study brings to light the fact that the percentage of bothersome hypesthesia is low $(0.3 \%)$ using a range of doses between 70 and $90 \mathrm{~Gy}$ with the retrogasserian target. This study provides reasonable long-term evidence of the very high safety and efficacy of GKS in CTN. Radiosurgery is a rational first-line neurosurgical option for $\mathrm{TN}$. The spectrum of complications clearly differs between different neurosurgical options and must be taken into account during the decision-making process. The rarity of the complications and the important probability of long-lasting effects prompt us to regard GKS as a pragmatic surgical first- and/or second-intention alternative for CTN. However, MVD remains as the reference technique, and further prospective randomized studies are still needed to compare the long-term efficacy of radiosurgery with MVD. We expect these studies to clarify the potential role of each approach. Neurosurgical techniques offer the highest chance of improving quality of life in patients with medically refractory TN. However, surgery is not indicated for all these patients; they should be informed about the full range of choices, and they must integrate the benefits and risks of each alternative in the decision-making process. The centers able to provide patients with all these techniques are better placed to contribute to these clarifications. 


\section{Acknowledgment}

This study was funded by Timone University Hospital, Assistance-Publique, Hopitaux de Marseille, France.

\section{References}

1. Barker FG II, Jannetta PJ, Bissonette DJ, Larkins MV, Jho HD: The long-term outcome of microvascular decompression for trigeminal neuralgia. N Engl J Med 334:1077-1083, 1996

2. Broggi G, Ferroli P, Franzini A, Servello D, Dones I: Microvascular decompression for trigeminal neuralgia: comments on a series of 250 cases, including 10 patients with multiple sclerosis. J Neurol Neurosurg Psychiatry 68:59-64, 2000

3. Brown JA, McDaniel MD, Weaver MT: Percutaneous trigeminal nerve compression for treatment of trigeminal neuralgia: results in 50 patients. Neurosurgery 32:570-573, 1993

4. Burchiel KJ: Percutaneous retrogasserian glycerol rhizolysis in the management of trigeminal neuralgia. J Neurosurg 69:361-366, 1988

5. Cruccu G, Gronseth G, Alksne J, Argoff C, Brainin M, Burchiel K, et al: AAN-EFNS guidelines on trigeminal neuralgia management. Eur J Neurol 15:1013-1028, 2008

6. Dhople AA, Adams JR, Maggio WW, Naqvi SA, Regine WF, Kwok Y: Long-term outcomes of Gamma Knife radiosurgery for classic trigeminal neuralgia: implications of treatment and critical review of the literature. Clinical article. J Neurosurg 111:351-358, 2009

7. Eller JL, Raslan AM, Burchiel KJ: Trigeminal neuralgia: definition and classification. Neurosurg Focus 18(5):E3, 2005

8. Flickinger JC, Pollock BE, Kondziolka D, Phuong LK, Foote RL, Stafford SL, et al: Does increased nerve length within the treatment volume improve trigeminal neuralgia radiosurgery? A prospective double-blind, randomized study. Int J Radiat Oncol Biol Phys 51:449-454, 2001

9. Gronseth G, Cruccu G, Alksne J, Argoff C, Brainin M, Burchiel K, et al: Practice parameter: the diagnostic evaluation and treatment of trigeminal neuralgia (an evidencebased review): report of the Quality Standards Subcommittee of the American Academy of Neurology and the European Federation of Neurological Societies. Neurology 71:11831190,2008

10. International Headache Society: The International Classification of Headache Disorders. Cephalalgia 24 (Suppl 1):1-151, 2004

11. Kanpolat Y, Savas A, Bekar A, Berk C: Percutaneous controlled radiofrequency trigeminal rhizotomy for the treatment of idiopathic trigeminal neuralgia: 25-year experience with 1,600 patients. Neurosurgery 48:524-534, 2001

12. Kondziolka D, Lunsford LD, Flickinger JC, Young RF, Vermeulen S, Duma CM, et al: Stereotactic radiosurgery for trigeminal neuralgia: a multiinstitutional study using the gamma unit. J Neurosurg 84:940-945, 1996

13. Kondziolka D, Zorro O, Lobato-Polo J, Kano H, Flannery TJ, Flickinger JC, et al: Gamma Knife stereotactic radiosurgery for idiopathic trigeminal neuralgia. J Neurosurg 112:758-765, 2010

14. Latchaw JP Jr, Hardy RW Jr, Forsythe SB, Cook AF: Trigeminal neuralgia treated by radiofrequency coagulation. J Neurosurg 59:479-484, 1983

15. Leksell L: Cerebral radiosurgery. I. Gammathalanotomy in two cases of intractable pain. Acta Chir Scand 134:585595,1968

16. Leksell L: Sterotaxic radiosurgery in trigeminal neuralgia. Acta Chir Scand 137:311-314, 1971

17. Linskey ME, Ratanatharathorn V, Peñagaricano J: A prospective cohort study of microvascular decompression and Gamma Knife surgery in patients with trigeminal neuralgia. J Neurosurg 109 Suppl:160-172, 2008
18. Lopez BC, Hamlyn PJ, Zakrzewska JM: Systematic review of ablative neurosurgical techniques for the treatment of trigeminal neuralgia. Neurosurgery 54:973-983, 2004

19. Love S, Coakham HB: Trigeminal neuralgia: pathology and pathogenesis. Brain 124:2347-2360, 2001

20. McCormack M, Alfirevic A, Bourgeois S, Farrell JJ, Kasperavičiūtė D, Carrington M, et al: HLA-A*3101 and carbamazepine-induced hypersensitivity reactions in Europeans. N Engl J Med 364:1134-1143, 2011

21. Merrison AF, Fuller G: Treatment options for trigeminal neuralgia. BMJ 327:1360-1361, 2003

22. Mullan S, Lichtor T: Percutaneous microcompression of the trigeminal ganglion for trigeminal neuralgia. J Neurosurg 59:1007-1012, 1983

23. North RB, Kidd DH, Piantadosi S, Carson BS: Percutaneous retrogasserian glycerol rhizotomy. Predictors of success and failure in treatment of trigeminal neuralgia. J Neurosurg 72:851-856, 1990

24. Piatt JH Jr, Wilkins RH: Treatment of tic douloureux and hemifacial spasm by posterior fossa exploration: therapeutic implications of various neurovascular relationships. Neurosurgery 14:462-471, 1984

25. Pollock BE: Radiosurgery for trigeminal neuralgia: is sensory disturbance required for pain relief? J Neurosurg 105 Suppl:103-106, 2006

26. Pollock BE, Phuong LK, Foote RL, Stafford SL, Gorman DA: High-dose trigeminal neuralgia radiosurgery associated with increased risk of trigeminal nerve dysfunction. Neurosurgery 49:58-64, 2001

27. Pollock BE, Schoeberl KA: Prospective comparison of posterior fossa exploration and stereotactic radiosurgery dorsal root entry zone target as primary surgery for patients with idiopathic trigeminal neuralgia. Neurosurgery 67:633-639, 2010

28. Rand RW, Jacques DB, Melbye RW, Copcutt BG, Levenick MN, Fisher MR: Leksell Gamma Knife treatment of tic douloureux. Stereotact Funct Neurosurg 61 (Suppl 1):93-102, 1993

29. Régis J, Arkha Y, Yomo S, Murata N, Roussel P, Donnet A, et al: [Radiosurgery in trigeminal neuralgia: long-term results and influence of operative nuances]. Neurochirurgie 55:213-222, 2009 (Fr)

30. Régis J, Carron R, Tuleasca C, Donnet A: Distal radiosurgical targeting for trigeminal neuralgia, in Sheehan JP, Gerszten PC (eds): Controversies in Stereotactic Radiosurgery: Best Evidence Recommendations. New York: Thieme, 2014, pp 120-130

31. Régis J, Manera L, Dufour H, Porcheron D, Sedan R, Peragut JC: Effect of the Gamma Knife on trigeminal neuralgia. Stereotact Funct Neurosurg 64 (Suppl 1):182-192, 1995

32. Régis J, Metellus P, Hayashi M, Roussel P, Donnet A, BilleTurc F: Prospective controlled trial of gamma knife surgery for essential trigeminal neuralgia. J Neurosurg 104:913924,2006

33. Régis J, Tuleasca C: Fifteen years of Gamma Knife surgery for trigeminal neuralgia in the Journal of Neurosurgery: history of a revolution in functional neurosurgery. $\mathbf{J}$ Neurosurg 115 Suppl:2-7, 2011

34. Rogers CL, Shetter AG, Fiedler JA, Smith KA, Han PP, Speiser BL: Gamma knife radiosurgery for trigeminal neuralgia: the initial experience of The Barrow Neurological Institute. Int J Radiat Oncol Biol Phys 47:1013-1019, 2000

35. Saini SS: Reterogasserian anhydrous glycerol injection therapy in trigeminal neuralgia: observations in 552 patients. J Neurol Neurosurg Psychiatry 50:1536-1538, 1987

36. Slettebø H, Hirschberg H, Lindegaard KF: Long-term results after percutaneous retrogasserian glycerol rhizotomy in patients with trigeminal neuralgia. Acta Neurochir (Wien) 122:231-235, 1993 
37. Tuleasca C, Carron R, Resseguier N, Donnet A, Roussel $\mathrm{P}$, Gaudart J, et al: Multiple sclerosis-related trigeminal neuralgia: a prospective series of 43 patients treated with gamma knife surgery with more than one year of follow-up. Stereotact Funct Neurosurg 92:203-210, 2014

38. Tuleasca C, Carron R, Resseguier N, Donnet A, Roussel P, Gaudart J, et al: Patterns of pain-free response in 497 cases of classic trigeminal neuralgia treated with Gamma Knife surgery and followed up for least 1 year. J Neurosurg 117 Suppl:181-188, 2012

39. Tuleasca C, Carron R, Resseguier N, Donnet A, Roussel $\mathrm{P}$, Gaudart J, et al: Trigeminal neuralgia related to megadolichobasilar artery compression: a prospective series of twenty-nine patients treated with gamma knife surgery, with more than one year of follow-up. Stereotact Funct Neurosurg 92:170-177, 2014

40. Tuleasca C, Carron R, Resseguier N, Donnet A, Roussel P, Gaudart J, et al: Repeat Gamma Knife surgery for recurrent trigeminal neuralgia: long-term outcomes and systematic review. J Neurosurg 121 Suppl:210-221, 2014

41. Vandertop WP, Lagerwaard FJ: Case 21-2006: a man with left-sided facial pain. N Engl J Med 355: 2375-2376, 2006

42. Xu Z, Schlesinger D, Moldovan K, Przybylowski C, Sun X, Lee CC, et al: Impact of target location on the response of trigeminal neuralgia to stereotactic radiosurgery. J Neurosurg 120:716-724, 2014

43. Young B, Shivazad A, Kryscio RJ, St Clair W, Bush HM: Long-term outcome of high-dose $\gamma$ knife surgery in treatment of trigeminal neuralgia. J Neurosurg 119:1166-1175, 2013

44. Zakrzewska JM, Akram H: Neurosurgical interventions for the treatment of classical trigeminal neuralgia. Cochrane Database Syst Rev 9:CD007312, 2011

45. Zakrzewska JM, Jassim S, Bulman JS: A prospective, longitudinal study on patients with trigeminal neuralgia who underwent radiofrequency thermocoagulation of the Gasserian ganglion. Pain 79:51-58, 1999
46. Zakrzewska JM, Lopez BC: Quality of reporting in evaluations of surgical treatment of trigeminal neuralgia: recommendations for future reports. Neurosurgery 53:110-122, 2003

47. Zakrzewska JM, Lopez BC, Kim SE, Coakham HB: Patient reports of satisfaction after microvascular decompression and partial sensory rhizotomy for trigeminal neuralgia. Neurosurgery 56:1304-1312, 2005

48. Zakrzewska JM, Thomas DG: Patient's assessment of outcome after three surgical procedures for the management of trigeminal neuralgia. Acta Neurochir (Wien) 122:225-230, 1993

\section{Disclosure}

Dr. Régis has a financial relationship with Accuray, Brainlab, Elektra, and Radionic and receives non-study-related clinical or research support from Elektra and Medtronic.

\section{Author Contributions}

Conception and design: Régis, Tuleasca, Levivier. Acquisition of data: Régis, Tuleasca, Donnet. Analysis and interpretation of data: Régis, Tuleasca, Levivier. Drafting the article: Régis, Tuleasca, Levivier. Critically revising the article: Régis, Tuleasca, Resseguier, Carron, Donnet, Levivier. Reviewed submitted version of manuscript: Régis, Tuleasca, Resseguier, Carron, Donnet, Levivier. Approved the final version of the manuscript on behalf of all authors: Régis. Statistical analysis: Resseguier, Gaudart. Administrative/technical/material support: Régis, Donnet, Gaudart, Levivier. Study supervision: Régis, Gaudart, Levivier.

\section{Correspondence}

Jean Régis, Functional and Stereotactic Neurosurgery Service and Gamma Knife Unit, 264, Rue Saint Pierre, Marseille 13385, France.email: jregis@ap-hm.fr. 